\title{
Chuvas intensas relacionadas à erosão hídrica
}

\author{
Glenio G. Santos' ${ }^{1}$, Nori P. Griebeler ${ }^{2}$ \& Luiz F. C. de Oliveira ${ }^{3}$
}

\begin{abstract}
RESUMO
As características das precipitações que mais interferem no processo de erosão do solo são a intensidade, a duração e a frequência da precipitação e a sua erosividade. Sendo o solo um recurso de renovação lenta e podendo ser rapidamente degradado pela ação da erosão, torna-se fundamental o conhecimento da forma como a precipitação atua no ambiente no qual esteja inserido. Desta forma se facilitam o desenvolvimento de técnicas e tecnologias e o estabelecimento de ações para diagnosticar, avaliar e apresentar soluções aos problemas, tanto econômica como ambientalmente. Diversos trabalhos, incluindo resultados de pesquisas e desenvolvimento de modelos, têm correlacionado as características das precipitações no sentido de entender, prever e apresentar soluções ao problema erosivo. Neste sentido se buscou compilar alguns desses trabalhos, de modo a apresentar o "estado da arte" no que se refere a chuvas intensas, manejo do solo e erosão hídrica.
\end{abstract}

Palavras-chave: escoamento superficial, intensidade-duração-frequência, modelos hidrológicos, perda de solo e água

\section{Intense rainfalls related to water erosion}

\begin{abstract}
The most important rainfall characteristics on erosion process are the relationship between intensity, duration and frequency of precipitation and its erosivity. As the soil is a slow renewal resource and can be quickly degraded by erosion, the knowledge about how the precipitation acts in the environment is fundamental. In this way, the development of techniques, technologies and the establishment of actions to diagnose, to evaluate and to present solutions to erosion problems is important both economically and environmentally. Many studies, including research results and development of models have correlated precipitations characteristics in order to understand, to predict and to present solutions for the erosion problem. In this sense, some of these studies were compiled with the purpose of presenting the "state of the art" with respect to precipitations, soil management and water erosion.
\end{abstract}

Key words: runoff, intensity-duration-frequency, hidroligic models, water and soil loss 


\section{INTRODUÇÃO}

A caracterização das chuvas intensas é imprescindível para solucionar problemas de interesse da engenharia, de modo especial o controle do escoamento superficial, em áreas urbanas e rurais. O uso de técnicas e modelos hidrológicos permite a caracterização e a quantificação do escoamento superficial originado de chuvas intensas utilizando-se, para tanto, hidrógrafas, que correlacionam a variação da descarga com o tempo ou se dispondo de modelos matemáticos, empíricos ou paramétricos ou mesmo modelos conceituais e determinísticos, que empregam métodos hidrológicos e hidráulicos.

A principal meta do hidrólogo não é simplesmente quantificar um evento hidrológico que ocorreu mas, essencialmente, ter a capacidade de prever a ocorrência de eventos extremos e suas possíveis consequências. Atualmente se utiliza cada vez mais modelos matemáticos que têm sido associados a Sistemas de Informações Geográficas (SIG) que permitem uma descrição espacial das características físicas da área de estudo. Apesar dessas considerações, os modelos apresentam deficiências em virtude das simplificações e adaptações necessárias para a sua utilização e também em razão de dificuldades na determinação dos parâmetros a serem utilizados.

Um dos grandes desafios é a determinação com nível de precisão da influência que os fatores ambientais e antrópicos têm sobre a erosão dos solos e as consequências desta para o sistema. A degradação do solo se dá principalmente pelo arraste das partículas menores e mais ricas em nutrientes, culminando com decréscimo da fertilidade e, consequentemente, pela redução das produções ou pelas crescentes necessidades da reposição de fertilizantes e corretivos. Na maioria dos casos, as perdas de solo causadas pela erosão hídrica reduzem a espessura do solo, diminuindo a capacidade de retenção e redistribuição da água no perfil gerando, como consequência, maiores escoamentos superficiais e, por vezes, maiores taxas de erosão do solo.

Os sedimentos, fertilizantes e agroquímicos, são arrastados e provocam problemas de assoreamento e poluição na rede hidrográfica, diminuindo a seção de vazão dos leitos dos rios e aumentando os riscos de cheias, o que compromete a perenidade dos cursos de água. A erosão hídrica dos solos e a consequente produção de sedimentos têm sido preocupação constante em todas as situações relativas à gestão do uso do solo e da água. Em regiões em que predominam os processos de meteorização química e os solos são escassos e pobres, sob condições climáticas de temperaturas e precipitações pluviométricas de alta variabilidade, esta preocupação se torna mais relevante.

Precipitações pluviométricas de maior intensidade e com grande frequência elevam o risco de ocorrência da erosão. Essas características são mais significativas quando associadas às condições de relevo movimentado, características físico-hídricas do solo adversas, uso e manejo do solo inadequados. A erosão hídrica proveniente de chuvas intensas tem ocasionado problemas de ordem ambiental, econômico e social relevantes ao equilíbrio natural dos agrossistemas em uso. Desta forma, a presente revisão pretende explorar os dados disponíveis sobre o tema, contribuindo para um co- nhecimento melhor dos trabalhos existentes na literatura relativos a chuvas intensas e seus efeitos sobre a erosão hídrica, manejo e qualidade do solo e da água.

\section{CHUVAS INTENSAS}

Segundo Tucci (2004), para elaboração de projetos de obras hidráulicas, tais como vertedores de barragens, sistemas de drenagem, galerias pluviais e dimensionamento de bueiros, dentre outros, faz-se necessário conhecer as três grandezas que caracterizam as precipitações máximas: intensidade, duração e frequência. Chen (1983), baseado em equacionamentos relacionados à precipitação e realizados por diversos autores, propôs um desenvolvimento matemático, para compor uma relação entre intensidade, duração e frequência de precipitação. Uma das formas de relacionar essas características da chuva é através da equação de chuva intensa, representada pela Eq. 1:

$$
\mathrm{i}_{\mathrm{m}}=\frac{\mathrm{KT}_{\mathrm{R}}^{\mathrm{a}}}{(\mathrm{t}+\mathrm{b})^{\mathrm{c}}}
$$

em que: $\mathrm{i}_{\mathrm{m}}$ é a intensidade máxima média de precipitação em $\mathrm{mm} \mathrm{h}^{-1}, \mathrm{~T}_{\mathrm{R}}$ é o período de retorno em anos e $\mathrm{K}$, a, b e c são parâmetros relativos à localidade.

Os parâmetros da equação de chuva intensa são obtidos por meio de regressão não-linear, com base nas informações extraídas de pluviogramas. A determinação da equação de chuva intensa, segundo Silva et al. (1999a) e Oliveira et al. (2005), apresenta grandes dificuldades em função da escassez de registros pluviográficos, dos obstáculos para sua obtenção, da baixa densidade da rede de pluviógrafos e do pequeno período de observações disponível. Ressaltam, ainda, que a metodologia para obtenção de registros exige um exaustivo trabalho de tabulação, análise e interpretação de uma grande quantidade de pluviogramas, razão por que poucos trabalhos têm sido desenvolvidos, no Brasil, com esta finalidade.

O trabalho clássico de estudos de chuvas intensas no Brasil foi publicado por Pfafstetter (1957), e os mais recentes são de Fendrich (1998) para o Estado do Paraná, Pinto et al. (1999) e Freitas et al. (2001) para o Estado de Minas Gerais, Silva et al. (1999a) e Martinez Júnior (1999) para o Estado de São Paulo, Costa \& Brito (1999) para o Estado de Goiás e duas cidades de Tocantins, Silva et al. (1999b; 2002; 2003) para os Estados do Rio de Janeiro, Espírito Santo, Bahia e Tocantins e Oliveira et al. (2005; 2008) para o Estado de Goiás e Distrito Federal.

Algumas metodologias (Log-Normal a dois e três parâmetros, Pearson tipo III, Log Pearson tipo III, Isozonas, DAEECETESB) foram desenvolvidas no País para a obtenção de chuvas de menor duração a partir de dados pluviométricos visto que existe, no território nacional, uma grande rede com dados pluviométricos sanando, em parte, os problemas apontados por Silva et al. (1999a) e Martinez Júnior (1999); referidas metodologias empregam coeficientes para transformar chuvas de 24 h em chuvas de menor duração e dentre elas estão as isozonas e DAEE-CETESB. O método das isozonas pro- 
posto por Torrico (1975) pela observação de áreas homólogas cuja relação entre as precipitações de 1 e 24 h, para um mesmo $T_{R}$, é constante e independente das alturas de precipitação. Esta relação constante permite determinar a correlação entre os dados de postos pluviográficos e pluviométricos, para tempos de duração de chuvas inferiores a 24 h, e a da desagregação da chuva de 24 h.

Segundo Costa \& Rodrigues (1999), a metodologia das isozonas tem sido empregada rotineiramente pelos órgãos responsáveis pelas estradas no Estado de Goiás (Departamento de Estrada e Rodagem do Estado de Goiás - DERGO, e Departamento Nacional de Estrada e Rodagem - DNER). Esses mesmos autores compararam os resultados obtidos pelo método das isozonas com os encontrados por meio de equações de chuvas intensas e acharam desvios entre 7,5 e 54,0\%, recomendando a busca de outra alternativa como metodologia de cálculo. Para se utilizar esta metodologia deve-se dispor de uma série histórica anual de dados de pluviômetros relativos às máximas chuvas diárias. Com base na série histórica estima-se a chuva de 1 dia para determinado $T_{R}$ empregando-se distribuições de probabilidade (Gumbel, por exemplo). A metodologia desenvolvida por DNOS e adotada pelo DAEE-CETESB (1980) é semelhante ao método das isozonas. Por esta metodologia, adota-se o fator médio de 1,14 para a transformação de chuva de 1 dia em chuva de 24 horas, obtido pela análise da correlação para diferentes $\mathrm{T}_{\mathrm{R}}$; já para os demais tempos de duração de chuvas, vide tabela de fatores em Oliveira et al. (2008).

Para locais em que não se dispõe de postos pluviográficos, pode-se recorrer a métodos de regionalização via sistema de informações geográficas e relações regionais, como o método de Bell (1969); por esta razão, trabalhos vêm sendo realizados com o objetivo de se ajustar uma distribuição teórica aos dados observados de chuvas, com a finalidade de se estimar valores para localidades desprovidas de postos pluviográficos. Sivapalan \& Blöschl (1998) ressaltam, porém, que os dados de chuva são avaliados como valores pontuais enquanto deveriam sê-lo na forma de distribuição temporal para uma efetiva caracterização de sua variabilidade, o que é imprescindível, por exemplo, para a análise de hidrógrafas. As funções densidade de probabilidade $f(x)$, e as funções de distribuição acumulada, $\mathrm{F}(\mathrm{x})$, das distribuições teóricas Log-Normal a dois parâmetros, Log-Normal a três parâmetros, Pearson tipo III, Log-Pearson tipo III e Gumbel, segundo Freitas et al. (2001), têm sido as mais utilizadas.

Mello et al. (1994) avaliaram a adequação da distribuição gama, de Erlang, log-normal e de valores extremos às amostras de totais pluviais máximos horários, para Campinas, SP, em que, com os resultados obtidos pelos autores, chegou-se à conclusão de que as distribuições foram adequadas para representar as amostras nos meses analisados, ocorrendo exceção para o mês de janeiro, visto que apenas as distribuições de Erlang e log-normal foram representativas. Sentelhas et al. (1998) analisaram e caracterizaram a distribuição horária de chuvas intensas com quatro horas de duração, para Piracicaba, SP, apresentando o modelo de distribuição com maior probabilidade de ocorrência, de outubro a março. Os resultados foram apresentados na forma de histo- grama, sendo a duração de quatro horas, subdividida em quatro intervalos iguais e sucessivos de uma hora. O modelo predominante em $85 \%$ dos casos, entre outubro e março, foi o exponencial negativo, com frações da precipitação total de $69,3 \%$ na primeira, de $16,3 \%$ na segunda, de $9,4 \%$ na terceira e de $5 \%$ na quarta hora, caracterizando uma chuva de distribuição adiantada (quando a maior intensidade ocorre em um período de tempo menor que $30 \%$ a partir do tempo inicial da chuva em relação ao tempo total de duração), frontal ou convectiva.

Em áreas urbanas, chuvas intensas provocam cheias nos sistemas de drenagem naturais e causam picos de escoamento nas galerias pluviais (Righetto, 1998), sendo seu estudo fundamental para a determinação da chuva de projeto para esses sistemas. No meio rural, o conhecimento das características das chuvas intensas é de grande importância, uma vez que a sua intensidade é fator expressivo no processo de erosão do solo (Reyes et al., 1993).

À exceção de Sentelhas et al. (1998), raros têm sido os trabalhos, no Brasil, envolvidos com a caracterização da distribuição temporal de chuvas intensas, ao passo que no exterior esse tipo de estudo é bastante comum (Huff, 1967). Segundo Cruciani et al. (2002), conhecer o modelo de distribuição temporal de chuvas intensas de uma localidade torna mais realista a previsão hidrológica em projetos de engenharia em áreas rurais e urbanas, permitindo a caracterização e a quantificação, com maior precisão, do escoamento superficial, o que pode ser efetuado pela aplicação de métodos de análise de hidrógrafas, como o conhecido método de Sherman e o do Soil Conservation Service, entre outros.

\section{EROSIVIDADE DAS CHUVAS}

Segundo a Organização de Agricultura e Alimentos das Nações Unidas (FAO, 1967), fator erosividade da chuva (R) é um índice numérico que expressa a capacidade da chuva esperada em dada localidade, de causar erosão em uma área sem proteção. As chuvas serão consideradas erosivas e individuais desde que sejam maiores ou iguais a $10 \mathrm{~mm}$ ou maiores ou iguais a $6,0 \mathrm{~mm}$, desde que ocorram em, no máximo, 15 min e separadas entre si por um período de no mínimo 6 h com uma lâmina de chuva de 1,0 mm ou menos (Wischmeier \& Smith, 1978; Almeida, 2009).

Para tanto é imprescindível a determinação do Fator " $R$ " na respectiva região climática. Conceitualmente, a erosividade da chuva (R) é descrita como uma interação entre a energia cinética e o momento do escoamento superficial. O índice de erosividade é função da intensidade e duração da precipitação, e da massa, diâmetro e velocidade da gota de chuva (Hudson, 1971). Para determinação do Fator "R" da USLE, registros pluviográficos de períodos de chuva de 20 a 30 anos devem ser analisados (Cassol et al., 2008). Dos fatores responsáveis no processo, a capacidade da chuva em causar erosão, ou seja, sua erosividade, é considerada como o fator mais ativo da erosão hídrica (Machado et al., 2008). O fator R ao longo do ano define a melhor época para o estabelecimento das práticas de manejo e conservação do solo (Val et al., 1986). 
Este fator pode servir ainda como parâmetro de suporte a trabalhos de extensão e assistência rural, pois permite definir épocas críticas quanto à ocorrência da erosão (Bertol, 1994). A determinação da erosividade da chuva envolve um trabalho exaustivo de seleção e leitura de uma série de registros de chuvas, sendo esses dados escassos e, muitas vezes, de difícil acesso (Mello et al., 2007). Tal fato faz com que informações relativas à erosividade estejam disponíveis apenas para pequeno número de localidades no Brasil (Moreira et al., 2008).

\section{ESCOAMENTO SUPERFICIAL}

De acordo com Chow \& Maidment (1988), o escoamento superficial é a parcela do ciclo hidrológico relacionado ao deslocamento das águas sobre superfícies do solo, até encontrar uma calha definida. É regido por leis físicas e representado, qualitativamente, por variáveis como vazão, profundidade e velocidade de escoamento (Tucci, 2004) e dependente de um grande número de fatores, sendo o relevo, a cobertura da bacia, modificações artificiais nos rios, a distribuição, duração e intensidade da precipitação e o tipo de solo, os mais importantes.

Uma fração do volume total precipitado é interceptada pela vegetação e o restante atinge a superfície do solo. Castilho et al. (1999) verificaram que a quantidade de precipitação interceptada pela cobertura vegetal, constituída predominantemente de cana-de-açúcar em uma grande bacia hidrográfica do Estado de São Paulo, é bastante expressiva, implicando em redução da parcela de escoamento superficial representada no balanço hídrico dessa bacia.

Portanto, quando assumido que o solo é um meio homogêneo com conteúdo inicial de umidade uniforme, o processo de infiltração se torna bastante complexo. Para muitos eventos de precipitação existe um período inicial durante o qual toda a precipitação se infiltra no solo. Durante este período e como a água se infiltra, a capacidade de infiltração decresce até se tornar menor que a intensidade de precipitação; a partir deste momento, a água começa a se acumular sobre a superfície do solo nas microdepressões e o escoamento superficial pode ocorrer (Pruski et al., 2004). Para representar adequadamente um evento em que haja produção de escoamento superficial, o hidrologista deve ser hábil não somente a predizer este instante mas, também, o momento em que se verifica o declínio na capacidade de infiltração (Mein \& Larson, 1973).

A rugosidade da superfície é uma propriedade dinâmica do solo que influencia muitos processos que ocorrem na superfície, afetando a infiltração, o armazenamento superficial, o escoamento superficial, a refletância solar, a liberação e o transporte de partículas associadas à erosão hídrica e o perfil do vento sobre a superfície do solo (Castro et al., 2006). Desta forma, Pruski et al. (2004) consideraram que o escoamento superficial é o principal processo associado à erosão hídrica e ocorre quando a intensidade da precipitação excede a taxa de infiltração da água no solo. Embora o impacto das gotas de chuva desempenhe importante papel na libera- ção das partículas de solo, é o escoamento da água que promove o transporte das partículas de solo liberadas para áreas em que ocorre o escoamento concentrado e, dependendo da carga de sedimentos e da capacidade de transporte do escoamento, é que ocorrerá a liberação ou a deposição dos sedimentos (Pruski et al., 2004). Muitas das práticas para o controle da erosão são, efetivamente, práticas para o controle da velocidade e do volume de escoamento superficial. Diversas aproximações têm sido feitas visando à consideração dos efeitos do escoamento superficial no processo erosivo, variando desde a desconsideração dos efeitos diretos do escoamento superficial até aquelas que consideram o perfil e a velocidade de escoamento da água.

Estimativas dos valores máximos de escoamento superficial são necessárias tanto em bacias hidrográficas com ocupação agrícola como urbana (Bonta \& Rao, 1992). Dados de volume máximo de escoamento superficial são oportunos em estudos de manejo do solo e da água, para determinar a eficiência dos métodos de preparo e manejo do solo e no planejamento de irrigação suplementar (Pathak et al., 1989). Eles também são usados no projeto de diques, canais e outras estruturas para o controle da erosão. Se o objetivo é reter ou armazenar todo o escoamento superficial, o conhecimento do volume total de escoamento superficial é suficiente mas, se o problema é transferir o excesso de água de um lugar para outro, torna-se imprescindível conhecer a vazão de escoamento superficial, especialmente a vazão correspondente a um período de retorno particular (Schwab et al., 1981).

Istok \& Boersma (1986) realizaram estudo com dados de chuva e de escoamento superficial para determinar a significância relativa das chuvas antecedentes no escoamento superficial em microbacias agrícolas do Norte dos Estados Unidos, durante eventos de chuvas de baixa intensidade (de 5-15 $\mathrm{mm} \mathrm{h}^{-1}$ ), concluindo que a umidade antecedente teve maior contribuição efetiva na quantidade de água escoada que a intensidade da precipitação. Bonta \& Rao (1992) mostraram a dificuldade em se aplicar a tecnologia disponível para estimar as vazões máximas de escoamento superficial, devido à imprecisão dos métodos normalmente usados e da grande discrepância obtida por diferentes projetistas que usam o mesmo procedimento; consequentemente, é de grande importância se obter um método confiável para estimar o escoamento superficial, ante o que Pruski et al. (1997) desenvolveram um procedimento para se calcular volume e vazão máxima de escoamento superficial em localidades nas quais a equação de intensidade, duração e frequência da precipitação, é conhecida.

\section{EROSÃO HÍDRICA E MANEJO DO SOLO}

Os processos erosivos ocorrem naturalmente no meio ambiente, de forma lenta e gradual causando, no decorrer da evolução do globo terrestre, mudanças no relevo e na vegetação (Bertoni \& Lombardi Neto, 1993). Sobretudo nas vertentes de bacias hidrográficas, a erosão hídrica é identificada como a principal causa do empobrecimento do solo agrícola, em cujo processo a estrutura do solo é destruída pelo 
impacto da chuva que atinge a superfície do terreno e, em seguida, o material solto, rico em nutrientes e matéria orgânica, é removido do local e depositado nas depressões no interior das vertentes e no fundo dos vales, tendo como resultado o assoreamento dos leitos dos rios (Pissarra et al., 2005). A intensidade de ação deste processo erosivo depende, além do clima, da resistência do solo e da presença de diversas condições ligadas ao manejo do solo e água e da natureza da comunidade vegetal presente (Bahia, 1992). A erosão hídrica do solo é influenciada pela chuva, solo, topografia, cobertura e manejo do solo e práticas conservacionistas (Pissarra et al., 2005).

A intervenção humana acelera esses processos erosivos por meio da ocupação e uso intensivo do solo, removendo paulatinamente as camadas superficiais do solo, chegando a formar sulcos e ravinas, quando o escoamento da água é torrencial (Endres et al., 2006). Os preparos de solo conservacionistas se caracterizam por pequena movimentação mecânica do solo, manutenção da maioria dos resíduos culturais sobre a superfície e, com exceção da semeadura direta, elevação da rugosidade superficial (Castro et al., 2006), o que torna esses sistemas de manejo mais eficazes no controle da erosão hídrica que os preparos convencionais (Schick, 1999). A semeadura direta, apesar da baixa rugosidade superficial que proporciona, possibilita o ancoramento de resíduos nos restos das culturas e, ainda, promove a consolidação da estrutura superficial do solo, o que aumenta a tensão crítica de cisalhamento e, consequentemente, a resistência do solo a erosão hídrica (Schick et al., 2000a).

Desta forma, a erosividade das chuvas é um fator que representa a capacidade que as chuvas têm de provocar a erosão ao solo. Fundamentalmente, a erosividade das chuvas depende da intensidade com que ocorrem e da energia cinética de impacto das gotas de chuva sobre a superfície do solo (Wischmeier \& Smith, 1958; Cassol \& Lima, 2003). Áreas cobertas com resíduos vegetais, como nos sistemas conservacionistas de preparo de solo, são menos susceptíveis à erosão hídrica. A cobertura superficial dissipa a energia da chuva e, em parte, protege a superfície do solo do selamento e, com isto, aumenta a infiltração e diminui o escoamento superficial e a erosão hídrica (Duley, 1939; Castro et al., 2006).

Dentre esses fatores, a cobertura do solo em função do manejo, apresenta maior influência sobre a erosão hídrica que os demais (Cogo, 1981). Áreas descobertas e fisicamente degradadas, típicas de sistemas convencionais de preparo de solo, sofrem alta erosão hídrica em decorrência da ação direta do impacto das gotas da chuva que desagregam e transportam partículas de solo, em especial pelo salpicamento (Wischmeier \& Smith, 1978; Castro et al., 2006), provocam selamento superficial (Duley, 1939), diminuem a retenção, infiltração e redistribuição de água no solo e aumentam o volume de escorrimento superficial (Burwell et al., 1966; Schick et al., 2000a).

Segundo Bertol (1989), as plantas de cobertura e o material orgânico no solo podem promover redução nas perdas de solo de até $90 \%$ e na velocidade da enxurrada de até $62 \%$. Comparando diferentes sistemas de preparo e cultivo do solo, Schick et al. (2000a) concluíram que o sistema plantio dire- to é mais eficaz no controle das perdas de solo, reduzindoas em 68 e 52\%, em relação ao manejo com uma aração associada a duas gradagens e escarificação associada a uma gradagem, respectivamente. As perdas de água seguem a mesma tendência, sendo menos influenciadas que as perdas de solo. Estudos indicam que os sistemas de manejo que deixam os resíduos culturais sobre a superfície do solo reduzem perdas de água por escoamento superficial; outros, no entanto, não indicam diferenças expressivas nas perdas de água quando varia o sistema de manejo (Schick et al., 2000a).

\section{EFEITOS ADVERSOS E ATENUANTES DA EROSÃO HÍDRICA}

Com base em estimativas de que o Brasil perde, por ano, quinhentos milhões de toneladas de terra por erosão e se supondo que nossos solos tenham, em média, $0,10 \%$ de nitrogênio $(\mathrm{N}), 0,15 \%$ de fósforo $\left(\mathrm{P}_{2} \mathrm{O}_{5}\right)$ e $1,5 \%$ de potássio $\left(\mathrm{K}_{2} \mathrm{O}\right)$, o montante de perdas desses nutrientes seria mais de oito milhões de toneladas (Pomianoski, 2005). A erosão hídrica do solo ocasiona perda de nutrientes (Bertol et al., 2003), além de contaminar os mananciais e outras áreas fora do local de origem da erosão (Schick et al., 2000b) e diminuir a produtividade agrícola pelo empobrecimento do solo (Bertoni \& Lombardi Neto, 1993). A contaminação dos mananciais, neste caso, é ocasionada pelo escoamento superficial, a qual transporta sedimentos coloidais que contêm nutrientes, em geral em altas concentrações. Além disso, a água do escoamento superficial transporta nutrientes solúveis, alguns deles em altas concentrações (Guadagnin, 2003), podendo provocar a eutrofização das águas onde se depositam.

A concentração de determinado nutriente no escoamento superficial varia principalmente com sua concentração no solo, que é influenciada pelo tipo de solo, pelas adubações e pelo tipo de manejo empregado. A quantidade total do nutriente transportado pela erosão hídrica, no entanto, depende da sua concentração no material erodido e do volume total desse material perdido pela erosão (Bertol et al., 2003). Estudos relativos à eficácia de sistemas conservacionistas de manejo do solo no controle de perdas de nutrientes indicam que o total de nutrientes perdidos por erosão hídrica decresce quando tais sistemas são utilizados, em relação aos convencionais (Guadagnin, 2003). Esta redução nos sistemas conservacionistas pode ser atribuída aos efeitos combinados do aumento da cobertura do solo com resíduos vegetais e consequente redução das perdas de solo e água apesar de, em geral, aumentar a concentração dos nutrientes na água e no sedimento perdidos pela erosão hídrica em tais sistemas (Schick, 1999).

Aliadas às práticas de manejo, as condições físicas de subsuperfície do solo também são importantes, haja vista que influenciam o movimento de água, calor e gases no seu interior e, decorrentemente, o escoamento superficial, germinação das sementes, crescimento inicial das raízes e desenvolvimento posterior das plantas (Volk et al., 2004). Dentre as condições físicas de subsuperfície do solo que influem na erosão se destacam aquelas que determinam a qualidade da 
estrutura e do espaço poroso do solo. A estrutura do solo é mais bem caracterizada por uma combinação de características e propriedades físicas do solo, não existindo uma variável simples que a represente adequadamente, em termos quantitativos (Sanchez, 1976).

Algumas práticas edáficas promovem modificações nas propriedades físicas do solo, principalmente na sua estrutura, podendo tais alterações ser permanentes ou temporárias e, ainda, influenciarem bastante o processo erosivo. Assim, o solo submetido a cultivo intensivo tem sua estrutura original alterada com fracionamento dos agregados em unidades menores e consequente redução no volume de macroporos e aumentos no volume de microporos e na densidade do solo (Panachuki et al., 2006).

A estabilidade e a distribuição relativa de tamanho de agregados e de poros do solo, são variáveis que servem para, indiretamente, avaliar a qualidade de sua estrutura (Kiehl, 1979). A estrutura tem efeito pronunciado na retenção, infiltração e armazenamento de água, na permeabilidade e erodibilidade do solo e na erosão hídrica levando, consequentemente, à perda de matéria orgânica e diminuição da fertilidade do solo (Mermut et al., 1997). Em geral, um solo com estrutura de boa qualidade apresenta boa capacidade de retenção, infiltração, permeabilidade e armazenamento de água no seu interior, o que, no conjunto, refletirá em menor erodibilidade (Volk et al., 2004). Em estudos dessa natureza, Streck \& Cogo (2003) observaram que a estabilidade de agregados tende a aumentar em solos cultivados com plantas que produzem elevada massa de raízes variando, no entanto, com a espécie vegetal, de acordo com as diferenças existentes na morfologia e distribuição de volume das raízes.

A constante redução da produtividade dos solos tem sido atribuída principalmente à erosão hídrica e ao manejo inadequado do solo. Outro aspecto de grande relevância é que o aporte de sedimentos oriundos de áreas que sofrem erosão promove o assoreamento de rios e lagos, comprometendo a qualidade da água e alterando a vida aquática, em particular pela eutrofização das águas (Martins et al., 2003).

Segundo Ramakrishma \& Davidson (1998), a erosão hídrica é um dos critérios a serem considerados quando se avalia a sustentabilidade de ambientes do solo sob floresta. A resistência dos solos a erosão hídrica apresenta grande amplitude, resultante da variabilidade climática, que influi na capacidade das chuvas em causar erosão, na variação de classes de solos com atributos diferenciados e manejo. Em sistemas agrícolas, autores têm obtido valores de perda de solo e água em vários sistemas de manejo, culturas e classes de solo. Pode-se citar a revisão de Silva et al. (1992), que encontraram perdas de solo variando de 0,1 a $31,8 \mathrm{t} \mathrm{ha}^{-1} \mathrm{ano}^{-1}$, tendo o plantio direto apresentado as menores perdas de solo, corroborando com os estudos de Nunes Filho et al. (1990), que trabalharam com perdas em Podzólico Vermelho-Amarelo textura franco-arenosa.

O monitoramento das perdas de solo por erosão hídrica, por comparação com os limites estabelecidos pela tolerância de perdas, é imprescindível ao manejo adequado das atividades agrícolas (Martins et al., 2003). Em virtude da necessidade de se produzir quantidades crescentes de alimentos e à impossibilidade de cultivar a terra sem riscos de erosão, estabeleceu-se um limite tolerável ou aceitável de perdas de solo, definido como sendo a intensidade máxima de erosão que ainda permitirá alto nível de produtividade das culturas de forma econômica, indefinidamente (Wischmeier \& Smith, 1978). Considera-se que a intensidade de erosão está dentro dos limites toleráveis quando não ultrapassa a intensidade de formação e renovação dos solos, tendo em vista que o solo, em determinado ponto da terra, representa um balanço entre remoção e enriquecimento, através das forças de erosão e pedogênese (Smith \& Stamey, 1965).

Segundo McCormarck et al. (1982), os critérios correntes para determinação da tolerância das perdas de solo são imperfeitos. Pouco se conhece das intensidades da pedogênese e dos efeitos da erosão na produtividade do solo. Para uma estimativa confiável são necessárias informações precisas sobre as intensidades de renovação do solo para diversas condições (Smith \& Stamey, 1965). A FAO (1967) admite perdas da ordem de $12,5 \mathrm{t} \mathrm{ha}^{-1} \mathrm{ano}^{-1}$, para solos profundos, permeáveis e bem drenados, 2-4 tha-1 $\mathrm{ano}^{-1}$, para solos rasos ou impermeáveis e, para outros solos, admite perdas intermediárias àqueles limites. A avaliação das perdas de solo e água assume importância fundamental na escolha e adoção de práticas que visem minimizar a degradação do solo (Martins et al., 2003). Apesar dos conceitos de perdas toleráveis de solo estarem muito relacionados à sua aptidão produtiva, é notória a necessidade de uma visão holística do problema, analisando a capacidade do ambiente em absorver os impactos produzidos pela erosão, incluindo fatores econômicos e sócio-ambientais.

Na literatura se encontram referências a um conjunto razoável de modelos para simulação da erosão hídrica do solo, dentre os quais a USLE - Empirical Soil Loss Model (Wischmeier \& Smith, 1958; 1978), WEPP - Water Erosion Prediction Project (Flanagan et al., 1995), EPIC - Erosion Productivity Impact Calculator (Sharpley \& Williams, 1990), SWAT - Soil and Water assessment Tool (SCS, 1972), CREAMS - Chemicals, Runoff, and Erosion from Agricultural Management Systems (Knisel, 1980), ANSWERS - Areal Nonpoint Source Watershed Environment Response Simulation (Beasley et al., 1980), EUROSEM - Soil Erosion Model for Europe (Morgan et al., 1998), AGNPS - Agricutural Non-Point Source Pollution (Young et al., 1987), KINEROS - Kinematic Erosion (Goodrich et al., 2000), CASC2D - Cascade Two-Dimensions (Ogden, 1998), TOPMODEL - (Szilagyi \& Parlange, 1999), HMS - Hydrologic Model System (Yu, 2000) e outros.

O planejamento integrado resulta em aumento expressivo na qualidade de água dos mananciais hídricos melhorando, desta forma, a qualidade de vida das populações beneficiadas (Silva, 1997). Segundo Roloff (1996), com a implantação do programa de manejo integrado em microbacias hidrográficas implantado no Estado do Paraná, denominado Paraná Rural, observou-se uma redução média de 50\% nos índices de turbidez da água utilizada para o abastecimento urbano; tais reduções chegaram a atingir, em algumas áreas, a ordem de 80\%. Richter (1995) encontrou reduções de 56,4\% nos índices de turbidez e de 10,4\% no 
custo de tratamento de água a partir do uso de práticas mecânicas de conservação do solo. Para Gassen \& Gassen (1996), a recuperação da qualidade da água foi uma das principais preocupações dos governos, decorrente da demanda da própria sociedade e comentaram, ainda, que a erosão nas lavouras e os resíduos urbanos foram os principais poluidores dos mananciais de água doce no Brasil.

\section{CONCLUSÕES}

1. As características das precipitações que mais interferem no processo de erosão do solo são a intensidade, a duração e a frequência com que as chuvas ocorrem e a sua erosividade.

2. Avanços recentes na pesquisa relacionada à precipitação estão pautados no aperfeiçoamento das bases metodológicas do século XX e no desenvolvimento e uso de modelos de predição e simulação.

3. Em modelos que envolvam a ocorrência de precipitações, um dos grandes inconvenientes é a incapacidade que esses modelos apresentam de caracterizar as chuvas, da forma como ocorrem, ignorando ou não distinguindo a variabilidade temporal e espacial.

4. Deficiências em dados e pesquisas com precipitação têm promovido a utilização de coeficientes obtidos com base em dados de regiões distintas daquelas nas quais são aplicados.

\section{LITERATURA CITADA}

Almeida, C. O. S. Erosividade das chuvas no Estado de Mato Grosso. Brasília: UNB, 2009. 81p. Dissertação Mestrado

Bahia, V. G. Fundamentos da erosão acelerada do solo (tipos, formas, mecanismos, fatores atuantes e controle). Informe Agropecuário, v.16, n.176, p.25-31, 1992.

Beasley, D. B.; Huggins, L. F.; Monke, E. J. ANSWERS: A model for watershed planning. Transactions of the ASAE, v.23, n.4, p.938-944, 1980.

Bell, F. G. Generalized rainfall-duration-frequency relationships. Journal of the Hydraulics Division, v.95, n.1, p.311-327, 1969.

Bertol, I. Degradação física do solo sob a cultura do alho. Revista Agropecuária Catarinense, v.2, p.47-50, 1989.

Bertol, I. Avaliação da erosividade da chuva na localidade de Campos Novos (SC) no período de 1981-1990. Pesquisa Agropecuária Brasileira, v.29, n.9, p.1453-1458, 1994.

Bertol, I.; Mello, E. L.; Guadagnin, J. C.; Zaparolli, A. L. V.; Carrafa, M. R. Nutrients losses by water erosion. Scientia Agricola, v.3, p.581-586, 2003.

Bertoni, J.; Lombardi Neto, F. Conservação do solo. 3.ed. São Paulo: Ícone, 1993. 355p.

Bonta, J. V.; Rao, A. R. Estimating peak flows from small agricultural watersheds. Journal of Irrigation and Drainage Engineering, v.118, n.1, p.122-137, 1992.

Burwell, R. E.; Allmaras, R. R.; Sloneker, L. L. Structural alteration of soil surfaces by tillage and rainfall. Journal of Soil and Water Conservation, v.21, p.61-63, 1966.
Cassol, E. A.; Eltz, F. L. F.; Martins, D.; Lemos, A. M.; Lima, V. S.; Bueno, A. C. Erosividade, padrões hidrológicos, período de retorno e probabilidade de ocorrência das chuvas em São Borja, RS. Revista Brasileira de Ciência do Solo, v.32, p.1239-1251, 2008.

Cassol, E. A.; Lima, V. S. Erosão em entressulcos sob diferentes tipos de preparo e manejo do solo. Pesquisa Agropecuária Brasileira, v.38, p.117-124, 2003.

Castilho, C. P. G.; Teixeira Filho, J.; Lulu, J. Interceptação de chuvas na cultura de cana-de-açúcar (Saccharum officinarum spp.). In: Simpósio Brasileiro de Recursos Hídricos, 8, 1999, Belo Horizonte. Resumos... Belo Horizonte: Associação Brasileira de Recursos Hídricos, 1999. CD-Rom.

Castro, L. G.; Cogo, N. P.; Volk, L. B. S. Alterações na rugosidade superficial do solo pelo preparo e pela chuva e sua relação com a erosão hídrica. Revista Brasileira de Ciência do Solo, v.30, p.339-352, 2006.

Chen, C. L. Rainfall intensity-duration-frequency. Journal of Hydraulic Engineering, v.109, n.12, p.1603-1621, 1983.

Chow, V. T.; Maidment, D. R. Applied hydrology. New York: McGraw-hill Book, 1988. 572p.

Cogo, N.P. Effect of residue cover, tillage induced-roughness, and slope lenght on erosion and related parameters. West Lafayette: Purdue University, 1981. 346p. These Doctored

Costa, A. R.; Brito, V. F. Equações de chuva intensa para Goiás e sul de Tocantins. In: Simpósio Brasileiro de Recursos Hídricos, 13, 1999, Belo Horizonte. Anais... Belo Horizonte: Associação Brasileira de Recursos Hídricos, 1999. CD-Rom.

Costa, A. R.; Rodrigues, A. A. Método das isozonas: Desvios entre resultados. In: Simpósio Brasileiro de Recursos Hídricos, 13, 1999, Belo Horizonte. Anais... Belo Horizonte: Associação Brasileira de Recursos Hídricos, 1999. CD-Rom.

Cruciani, D. E.; Machado, R. E.; Sentelhas, P. C. Modelos da distribuição temporal de chuvas intensas em Piracicaba, SP. Revista Brasileira de Engenharia Agrícola e Ambiental, v.6, n.1, p.76-82, 2002.

DAEE-CETESB. Departamento de Água e Energia Elétrica Companhia de Tecnologia de Saneamento Ambiental. Drenagem urbana: Manual de projeto. São Paulo: DAEE-CETESB, 1980. 466p.

Duley, F. L. Surface factors affecting the rate of intake of water by soils. Soil Science Societed of American Journal, v.4, p.60-64, 1939.

Endres, P. F.; Pissarra, T. C. T.; Borges, M. J.; Politano, W. Quantificação das classes de erosão por tipo de uso do solo no município de Franca, SP. Engenharia Agrícola, v.26, n.1, p.200-207, 2006.

FAO - Food and Agriculture Organization of the United Nations. La erosion del suelo por el água: Algunas medidas para combatirla en las tierras de cultivo. Roma: Organization de Las Nacioes Unidas, 1967. 207p.

Fendrich, R. Chuvas intensas para obras de drenagem no Estado do Paraná. Curitiba: Champagnat, 1998. 99p.

Flanagan, D. C.; Ascough II, J. C.; Nicks, A. D.; Nearing, M. A.; Laflen, J. M. Overview of the WEPP erosion prediction model. In: Flanagan, D. C.; Nearing, M. A. (ed.). Water erosion prediction project: Hillslope profile and watershed model documentation. West Lafayette: United States Department of Agriculture: National Soil Erosion Research Laboratory, 1995. p.1.1-1.12 (NSERL Report, 10).

R. Bras. Eng. Agríc. Ambiental, v.14, n.2, p.115-123, 2010. 
Freitas, A. J. D.; Silva, D. D. D.; Pruski, F. F.; Pinto, F. A.; Pereira, S.B.; Gomes Filho, R. R.; Teixeira, A. D. F.; Baena, L. G. N.; Mello, L. T. A. D.; Novaes, L. F. D. Equações de chuvas intensas no Estado de Minas Gerais. Belo Horizonte: Companhia de Saneamento de Minas Gerais; Viçosa: Universidade Federal de Viçosa. 2001. 65p.

Gassen, D. N.; Gassen, F.R . Plantio direto o caminho do futuro. Passo Fundo: Aldeia Sul, 1996. 207p.

Goodrich, D. C.; Kepner, W. G.; Hernandez, M.; Jones, B.; Edmonds, C. Landscape indicator interface with hydrologic models - Research plan. EPA/600/R-00/42. Washington: Environment Protection Agency. 2000. 57p.

Guadagnin, J. C. Perdas de nutrientes e carbono orgânico pela erosão hídrica, em um Cambissolo Húmico Alumínico léptico submetido a diferentes sistemas de preparo e cultivo do solo. Lages: UDESC, 2003. 150p. Dissertação Mestrado

Hudson, N. Soil conservation. Ithaca: Cornell University Press, 1971. 320p.

Huff, F. A. Time distribution of rainfall in heavy storms. Water Resource Research, v.3, n.4, p.1007-1019, 1967.

Istok, J. D.; Boersma, L. Effect of antecedent rainfall on runoff during low-intensity rainfall. Journal of Hydrology, v.88, p.329-342, 1986.

Kiehl, J. E. Manual de edafologia. São Paulo: Agronômica Ceres, 1979. 262p.

Knisel, W. G. CREAMS, a field scale model for chemicals, runoff and erosion from agricultural management systems. Washington: USDA Conservation, 1980. 89p. Research Report, 26

Machado, R. L.; Carvalho, D. F.; Costa, J. R.; Oliveira, D. H.; Pinto, M. F. Análise da erosividade das chuvas associada aos padrões de precipitação pluvial na região de Ribeirão das Lajes (RJ). Revista Brasileira de Ciência do Solo, v.32, p.2113-1223, 2008.

Martinez Júnior, F. Análise das precipitações intensas no Estado de São Paulo. In: Simpósio Brasileiro de Recursos Hídricos, 13, 1999, Belo Horizonte. Anais... Belo Horizonte: Associação Brasileira de Recursos Hídricos, 1999. CD-Rom.

Martins, S. G.; Silva, M. L. N.; Curi, N.; Ferreira, M. M.; Fonseca, S.; Marques, J. J. G. S. M. Perdas de solo e água por erosão hídrica em sistemas florestais na região de Aracruz (ES). Revista Brasileira de Ciência do Solo, v.27, p.395-403, 2003.

McCormarck, D. E.; Young, K. K.; Kimberlin, L. W. Current criteria for determining soil loss tolerance. In: Kral, D. M. (ed.). Determinants of soil loss tolerance. Madison: American Society of Agronomy, 1982. p.95-111. ASA Special Publication, 45 .

Mein, R. G.; Larson, C. L. Modeling infiltration during a steady rain. American Geophysical Union, v.9, n.2, p.384-394, 1973.

Mello, C. R.; Sá, M. A. C.; Curi, N.; Mello, J. M.; Viola, M. R.; Silva, A. M. Erosividade mensal e anual da chuva no Estado de Minas Gerais. Pesquisa Agropecuária Brasileira, v.42, n.4, p.537-545, 2007.

Mello, M. H. A.; Arruda, H. V.; Ortolani, A. A. Probabilidade de ocorrência de totais pluviais máximos horários, em Campinas, São Paulo. Revista IG, v.15, n.1/2, p.59-67, 1994.
Mermut, A. R.; Luk, S. H.; Romkens, M. J. M.; Poesen, J. W. A. Soil loss by splash and wash during rainfall from two loss soils. Geoderma, v.75, n.3, p.203-214, 1997.

Moreira, M. C.; Pruski, F. F.; Oliveira, T. E. C.; Pinto, F. A. C.; Silva, D. D. NetErosividade MG: Erosividade da chuva em Minas Gerais. Revista Brasileira de Ciência do Solo, v.32, p.1349-1353, 2008.

Morgan, R. P. C.; Quinton, J. N.; Smith, R. E.; Govers, G.; Poesen, J. W. A.; Auerswald, K.; Chisci, G.; Torri, D.; Styczen, M. E.; Folly, A. J. V. The European soil erosion model (EUROSEM): Documentation and user guide. Version 3.6. Silsoe College: Bedford, 1998. 124p.

Nunes Filho, J.; Sousa, A. R.; Mafra, R. C.; Silva, A. B. Práticas conservacionistas e as perdas por erosão na cultura do milho isolado e consorciado no Sertão do Pajeú (PE). Revista Brasileira de Ciência do Solo, v.14, p.69-72, 1990.

Ogden, F. J. CASC2D Reference manual. Storrs: Department of Civil end Environmental Engineering/University of Connecticut, 1998. 83p.

Oliveira, L. F. C.; Antonini, J. C. A.; Fioreze, A. P.; Silva, M. A. S. Métodos de estimativa de precipitação máxima para o Estado de Goiás. Revista Brasileira de Engenharia Agrícola e Ambiental, v.12, n.6, p.620-625, 2008.

Oliveira, L. F. C.; Cortês, F. C.; Wehr, T. R.; Borges, L. B.; Sarmento, P. H. L.; Griebeler, N. P. Intensidade-duração-frequência de chuvas intensas para localidades no Estado de Goiás e Distrito Federal. Pesquisa Agropecuária Tropical, v.35, n.1, p.13-18, 2005.

Panachuki, E.; Sobrinho, T. A.; Vitorino, A. C. T.; Carvalho, D. F.; Urchei, M. A. Parâmetros físicos do solo e erosão hídrica sob chuva simulada, em área de integração agricultura-pecuária. Revista Brasileira de Engenharia Agrícola e Ambiental, v.10, n.2, p.261-268, 2006.

Pathak, P.; Laryea, K. B.; Sudi, R. A runoff model for small watersheds in the semi-arid tropics. Transactions of the ASAE, v.32, n.5, p.1619-1624, 1989.

Pfafstetter, O. Chuvas intensas no Brasil. Brasília: Departamento Nacional de Obras e Saneamento, 1957. 246p.

Pinto, F. A.; Ferreira, P. A .; Pruski, F. F.; Alves, A. R.; Cecon, P. R. Equações de chuvas intensas para algumas localidades do Estado de Minas Gerais. Engenharia Agrícola, v.16, n.1, p.91-104, 1999.

Pissarra, T. C.; Galbiatti, J. A.; Borges, M. J.; Rosalen, D.; Iha, D. Avaliação por fotointerpretação do uso/ocupação do solo e erosão acelerada em microbacias hidrográficas utilizando sistemas de informação geográfica. In: Simpósio Brasileiro de Sensoriamento Remoto, 12, 2005, Goiânia. Anais... Goiânia: INPE, 2005. CD-Rom.

Pomianoski, D. J. W. Perdas de solo e água em sistemas agroflorestais da bracatinga (Mimosa scabrella Bentham) em diferentes declividades e manejos. Curitiba: UFPR, 2005. 91p. Dissertação Mestrado

Pruski, F. F.; Brandão, V. S.; Silva, D. D. Escoamento superficial. Viçosa: UFV, 2004. 87p.

Pruski, F. F.; Ferreira, P. A.; Ramos, M. M.; Cecon, P. R. Model to design level terraces. Journal of Irrigation and Drainage Engineering, v.23, n.1, p.8-12, 1997. 
Ramakrishma, K.; Davidson, E. A. Intergovernamental negotiations on criteria and indicators for the management, conservation, and sustainable development of forests: what role for forest soil scientists? In: Adams, M. B.; Ramakrishna, K.; Davidson, E. A. (ed.). The contributionof soil science to the development of and implementation of criteria and indicators of sustainable forests management. Madison: Soil Science Society of America, 1998. p.1-15. Special Publication, 53.

Reyes, M. R.; Bengtson, R. L.; Robbins, K. D. Rip and Wmrip. New measures of rainfall intensity distribution. Transactions of the ASAE, v.36, n.6, p.1619-1623, 1993.

Richter, A. S. Contribuições do controle da erosão dos solos em microbacias hidrográficas para a melhoria da qualidade da água no Rio Ampére. In: Congresso Brasileiro de Ciência do Solo, 25, 1995, Viçosa. Resumos... Viçosa: SBCS, 1995. p.2111-2113.

Righetto, A. M. Hidrologia e recursos hídricos. São Carlos: EESC/ USP, 1998. 819p.

Roloff, G. A experiência paranaense no manejo de microbacias hidrográficas. In: Alvarez, V. V. H.; Fontes, L. E. F.; Fontes, M. P. F. (ed.). O solo nos grandes domínios morfoclimáticos do Brasil e o desenvolvimento sustentado. Viçosa: SBCS, 1996. p.781-796.

Sanchez, P. A. Properties and management of soil in the tropics. New York: John Wiley and Sons, 1976. 618p.

Schick, J. Erosão hídrica em Cambissolo Húmico álico submetido a diferentes sistemas de preparo e cultivo do solo. Lages: UDESC, 1999. 114p. Dissertação Mestrado

Schick, J.; Bertol, I.; Batistela, O.; Balbinot Júnior, A. A. Erosão hídrica em Cambissolo Húmico alumínico submetido a diferentes sistemas de preparo e cultivo do solo: I. Perdas de solo e água. Revista Brasileira de Ciência do Solo, v.24, p.427-436, 2000a.

Schick, J.; Bertol, I.; Batistela, O.; Balbinot Júnior, A. A. Erosão hídrica em Cambissolo Húmico alumínico submetido a diferentes sistemas de preparo e cultivo do solo: II. Perdas de solo e água. Revista Brasileira de Ciência do Solo, v.24, p.437-447, 2000b.

Schwab, G. O.; Frevert, R. K.; Edminster, T. W.; Barnes, K. K. Soil and water conservation engineering. 3.ed. New York: John Wiley and Sons, 1981. 683p.

SCS - Soil Conservation Service. Department of Agriculture USA. Hydrology.Washington: USDA, 1972. 145p.

Sentelhas, P. C.; Cruciani, D. E.; Pereira, A. S.; Villa Nova, N. A. Distribuição horária de chuvas intensas de curta duração: um subsídio ao dimensionamento de projetos de drenagem superficial. Revista Brasileira de Meteorologia, v.13, n.1, p.45-52, 1998.

Sharpley, A. N.; Williams, J. R. Erosion/productivity impact calculator. Model documentation. Washington: USDA ARS Techinical, 1990. 235p. Bulletin 1768.

Silva, D. D.; Gomes Filho, R. R.; Pruski, F. F.; Pereira, S. B.; Novaes, L. F. Chuvas intensas para o Estado da Bahia. Revista Brasileira de Engenharia Agrícola e Ambiental, v.6, n.2, p.362-367, 2002.

Silva, D. D.; Pereira, S. B.; Pruski, F. F.; Gomes Filho, R. R.; Lana, A. M. Q.; Baena, L. G. N. Equações de Intensidade-Duração-Frequência da precipitação pluvial para o Estado de Tocantins. Engenharia na Agricultura, v.11, n.1-4, p.7-14, 2003.
Silva, D. D.; Pinto, F. R. L. P.; Pruski, F. F.; Pinto, F. A. Estimativa e espacialização dos parâmetros da equação de intensidade-duração-frequência da precipitação para os Estados do Rio de Janeiro e Espírito Santo. Revista Engenharia Agrícola, v.18, n.3, p.11-21, 1999b.

Silva, D. D.; Valverde, A. E. L.; Pruski, F. F.; Gonçalves, R. A. B. Estimativa e espacialização dos parâmetros da equação de intensidade-duração-frequência da precipitação para o Estado de São Paulo. Revista Engenharia na Agricultura, v.7, n.2, p.70-87, 1999a.

Silva, J. C. C. Planejamento integrado em microbacias hidrográficas. In: Silva D. D.; Pruski, F. F. (ed.). Recursos hídricos e o desenvolvimento sustentável da agricultura. Brasília: MMA/ SRH/ABEAS, Viçosa: UFV/DEA, 1997. p.115-128.

Silva, M. L. N.; Bahia, V. G.; Barroso, D. G. Perdas de solo em sistemas de preparo convencional e plantio direto. Informe Agropecuário, v.16, p.44-50, 1992.

Sivapalan, M.; Blöschl, G. Tranformation of point rainfall to areal rainfall: intensity-duration-frequency curves. Journal of Hydrology, v.204, n.1-4, p.150-167, 1998.

Smith, R. M.; Stamey, W. L. Determining the range of tolerable erosion. Soil Science, v.100, p.414-424, 1965.

Streck, E.V.; Cogo, N. P. Reconsolidation of the soil surface after tillage discontinuity, with and without cultivation, related to erosion and its prediction with RUSLE. Revista Brasileira de Ciência do Solo, v.27, p.141-152, 2003.

Szilagyi, J.; Parlange, M.B. A geomorphology-based semi-distributed watershed model. Advances in Water Resources, v.23, p.177-187, 1999.

Torrico, J. J. T. Práticas hidrológicas. Rio de Janeiro: Transcom, 1975. 120p.

Tucci, C. E. M. Hidrologia: Ciência e aplicação. 3.ed. Porto Alegre: UFRGS/ABRH, 2004. 943p.

Val, L. A.; Bahia, V. G.; Freire, J. C.; Dias Júnior, M. S. Erosividade das chuvas em Lavras, MG. Ciência e Prática, v.10, n.2, p.199-209, 1986.

Volk, L. B. S.; Cogo, N. P.; Streck, E. V. Erosão hídrica influenciada por condições físicas de superfície e subsuperfície do solo resultantes do seu manejo, na ausência de cobertura vegetal. Revista Brasileira de Ciência do Solo, v.28, p.763-774, 2004.

Wischmeier, W. H.; Smith, D. D. Rainfall energy and its relationship to soil loss. Transactions, American Geophysical Union, v.39, n.2, p.285-291, 1958.

Wischmeier, W. H.; Smith, D. D. Predicting rainfall erosion losses: A guide to conservation planning. Washington: USDA, 1978. 58p.

Young, R. A.; Onstad, C. A.; Bosch, D. D.; Anderson, W. P. AGNPS - Agricultural Non-Point Source Pollution Model - A watershed analysis tool. United Satates Department of Agriculture, Conservation Research Report. Washington: USDA, v.35, p.1-80, 1987.

$\mathrm{Yu}, \mathrm{Z}$. Assessing the response of su grid hudrologic processes to atmospheric forcing with a hydrologic model system. Global and Planetary Change, v.25, p.1-17, 2000. 